\title{
FORUM
}

\section{Interpretation and Behaviour in using Radar at Sea}

\author{
from Lieutenant Commander D. A. Davies, R.N.R.
}

I sHould like to make some comment on Captain Wylie's article in the January issue of the Journal $(\mathbf{1 8}, \mathbf{2 7})$. While not disputing his arithmetic I should like to state that in practice true motion is much more effective than he implies. For two years I used an Escort true motion set on the Southampton, Cherbourg, New York run and I can say most unequivocally that ships did not have to be proceeding at 18 knots to get satisfactory trails on the 12 -mile range scale. In fact one could see useful trails when ships were proceeding reasonably slowly.

When making a passage through such congested waters as the English Channel, with perhaps as many as 20 echoes on the radar screen, it is surely of the utmost importance that the potential risks should be ascertained as soon as possible in order that they can be carefully watched and perhaps plotted. Out of 20 echoes on the screen it often happens that only 2 or 3 are potential risks; the great value of true motion is that one gets a general picture of trails very rapidly and so can soon spot the potential risks; this allows early and substantial action to be taken.

I agree that a plot is also desirable, but unless the ship is equipped with an automatic plot or sufficient personnel it does not seem possible when there are a large number of echoes on the screen. Of course, there is no reason why, on the average ship in congested waters, the Officer of the Watch should not be on the true motion set, with an Apprentice making a plot of the potential risks and the Master in charge of the overall tactical situation. However, if there is no automatic plot, nor sufficient personnel, then surely true motion must be a better buy than relative motion in congested waters.

It must follow that in certain circumstances it could be construed as negligence for a vessel not to use her true motion. There is no difference between the rules of Common Law and Admiralty as to what constitutes negligence. The principle was stated by Lord Blackburn in the case of Cayzer $v$ Carron when he said that 'where anyone transgresses a navigation rule, whether it is a statutory rule, or whether it is a rule that is imposed by common sense and thereby an accident occurs of which that transgression is the cause, he is to blame'. This statement was reiterated in the Heranger, a case which went to the House of Lords in 1939, Lord Wright stating that the ordinary rule in common law cases is equally the rule in Admiralty. The common law rule is that THE STANDARD OF CARE IS THAT OF THE REASONABLE MAN SO THAT A BREACH OF DUTY CONSISTS IN THE OMISSION TO DO SOMETHING WHICH A REASONABLE MAN WOULD DO OR THE DOING OF SOMETHING WHICH A REASONABLE MAN WOULD NOT DO.

In the Oriana-Kearsage case the American judge decided that, inter alia, the Oriana was negligent in not using her true motion; he made this decision after an analysis of a huge mass of documentary evidence, but unfortunately he did not give a detailed account of this evidence in his judgment. Although the judgment seems 
rather erratic in some other aspects, I suggest that if the Oriana could have obtained reasonable trails from her true motion (a point we shall seemingly never know) then perhaps the judge was justified in finding that the Oriana was omitting to use an instrument WHICH a REASONABLE SEAMAN SHOULD HAVE USED IN THE CIRCUMSTANCES.

It has been stated many times in the English Courts that the categories of negligence are never closed, and to my mind there seems no reason why, under certain circumstances, the omission to use a true motion presentation should not be construed as negligence if reasonable trails are visible.

To complete my comment I should like to refer to the case of the Nora, in which Mr. Justice Willmer, as he then was, gave judgment in 1956. The collision was in poor visibility, one vessel being equipped with radar. The Judge had these pertinent comments to make about the ship with radar: "'For unto whomsoever much is given of him shall much be required." The possession of radar equipment gives such a vessel a great advantage over other vessels which are not similarly equipped, but it brings with it, in my judgment, a concurrent duty to see that intelligent and reasonable use is made of the equipment provided. If she makes a mistake, being so much better equipped than the other vessel, so much the less does she have an excuse for doing so'.

These words of wisdom can surely be applied to the question of the use of true motion in certain circumstances.

\section{Captain F. J. Wylie, R.N., comments:}

Lieutenant Commander Davies's letter seems to have two objects: to show that true motion in the right circumstances can be most effective and that it is possible for a ship to be negligent in failing to use true motion. My article does not deny either of these propositions; it deals with the complex of factors affecting trail length and seeks a minimum usable standard. It also suggests that the speed of the Kearsage was well below the suggested minimum for most of the approach period. It deals with plotting in rather the same manner showing that, in certain circumstances, it is useless for prediction and that these circumstances were present in the Oriana case.

Lieutenant Commander Davies speaks of the use of true motion to measure potential risks. Most people with whom I have discussed this agree that the best measure of risk is the predicted C.P.A. distance and time. This is not directly obtainable with true motion.

As I said in my article, the subject is controversial. There are wide differences of opinion between radar users; until these have been reconciled it would be presumptuous to express more than tentative opinions. 